\title{
A Systematic Review on Parasite Induced Carcinogenesis
}

\author{
Avinaba Mukherjee* \\ *Assistant Professor \\ *Department of Zoology, Charuchandra College, University of Calcutta, Kolkata-700029, India \\ 22, Lake Road, Kolkata 700029
}

\begin{abstract}
Parasitic pathogens through cross infection exert carcinogenesis in human body. The immune evasion strategy that has been adapted by several parasites is recognized to be associated with human carcinogenicity. In this review, studies have been analyzed which depicts how carcinogenicity occurs through several parasitic infection. Among the parasites that are involved toward developing carcinogenicity, Helminth is found to be dominant as per the recent studies. One reason for this that they mostly have prolonged life cycle than the other parasites, therefore more complex network through molecular endeavour has been adapted by them that would leads the host cell malignancy. This review particularly summarizes the parasites that are involved in carcinogenicity and the mechanism that they adapt to develop so. Targeting the molecules that are being modulated by parasites to trigger carcinogenesis, drug development can be done. Drug designing can also be made by targeting the parasite induced secretory molecules which mainly cross talk to develop carcinogenicity. Specially conjugated therapy of parasitic drugs with anticancer drugs that are target specific should be used at minimum doses so that to block the parasite induced carcinogenicity in host body.
\end{abstract}

Keywords:- Parasites; Pathogen; Carcinogenicity; Drug Target.

Short title: Carcinogenesis induced by Parasites

\section{INTRODUCTION}

Cancer is characterized by proliferative cells that survive in an uncontrollable manner. Several reasons are there that help to develop cancer in human body. Among them the most recent cause of carcinogenic event is mediated largely by parasitic attack. Parasites are found to be dominant in progression of carcinogenesis in several organs particularly in liver, stomach, colon and esophagus [1], [2]. It was reported that, eleven species of pathogens include Opisthorchis viverrini, Clonorchis sinensis, Schistosoma haematobium, Helicobacter pylori, hepatitis B virus (HBV), hepatitis C virus (HCV), human papillomavirus (HPV), Epstein-Barr virus (EBV), human Tcell lymphotropic virus type $\mathbf{1}$ (HTLV-1), human herpes virus type 8 (HHV-8) and human immunodeficiency virus type 1 (HIV-1) [3], [4], [5] associated with cancers are classified as Group 1 carcinogens. Recent studies indicated the Protozoa, Platyhelminthyes and Aschelmintheyes as the major parasites that exerts malignancy in human body. Parasite induced modulation the host immune system for their better survivability. However, this adaptive strategy that they take in host body makes the cells to be carcinogenic as the molecules that they modulate sometimes cross talk with the major molecules that are responsible for carcinogenicity. This is how the parasites unknowingly trigger cancer in host body. Through this review, we summarize current facts on associations of parasite infections, the mechanistic action that are responsible for parasite mediated carcinogenicity. Also we have enlightened the area that should be targeted by drug so that to prevent this parasite mediated carcinogenicity in near future.

\section{PARASITES INVOLVED IN CANCER AND THEIR MECHANISM TOWARDS CARCINOGENESIS}

\section{A. Protozoa as pathogen}

Among Protozoa major parasites like Plasmodium falciparum, Plasmodium vivax, Plasmodium ovale, Plasmodium malariae, Plasmodium knowlesi causes Burkitt lymphoma through expansion of the EBV-infected B cell population, suppressing the EBV-specific T-cell immunity [6], [7], [8], [9], [10], [11], [12].

Beside them, Theileria parva and Theileria annulata infections lead to the transformation of the leukocyte infected cells. They are also involved in stimulation of antiapoptosis signaling pathway by the activation of the transcription factor NF- $\kappa \mathrm{B}$. Along with this, modulating the cytokine imbalance particularly of GM-CSF (= granulocyte macrophage colony stimulating factor) secretion that help in the enhancement and re-stimulation of infected host cell proliferation via autocrine loops. GM-CSF also contributes to the induction of the factor c-Myc, leading to lymphocyte proliferation. Theileria induces the cellular transformation which leads to the constitutive activation of c-jun kinase (JNK) and permanent induction of activator protein 1 (AP1). Theileria alters host-cell actin dynamics, increases motility and enables infected host-cell to behave as leukocyte metastasis [13], [14], [15], [16], [17], [18].

Toxoplasma gondii infects warm blooded animals including humans and exerts chronic infection in the central nervous system after invasion. Thus it promotes brain carcinogenesis by altering the host miRNA using parasitic proteins and/or miRNAs [19], [20]. 
Among protozoa, Leishmania donovani exerts the activation of macrophages and dendritic cells during its pathogenesis and thus in case of chronic infections causes CD4 lymphopenia and low $\mathrm{CD} 4 / \mathrm{CD} 8$ ratio leading to Hodgkin's disease [21].

On the other hand, Giardia $\boldsymbol{s p}$ in case of long term and chronic infection can induce gastric cancer also [22], [23]. Intestinal abscess induced by them during infection can also led into intestinal cancer [24].

Trichomonas vaginalis infection is associated with cervical neoplasia. $\boldsymbol{T}$. vaginalis may be an inducer of cervical neoplasia by secreting propionic and isovaleric acids [25], [26], [27].

Cryptosporidium parvum generates invasive gastrointestinal cancer and alters the architecture of biliary epithelia. Apc is downregulated by this parasite leading to cytosolic $\beta$-catenin accumulation which alters the transcriptional regulation of infected cells [28], [29]. It also downregulates apoptotic mechanism, an effect that could be a significant step in the progression of malignancy

\section{B. Platyhelminthes as pathogen}

Several Platyhelminthes particularly under the family Opisthorchiidae, like Opisthorchis viverrini induces intestinal carcinoma and cholangiocarcinoma. Infection with the liver fluke Opisthorchis viverrini leads to bile duct cancer. Fluke releases thioredoxin (Trx) which help the cancer cell to survive, to promote angiogenesis, and to inhibit apoptosis by interacting with apoptosis signalregulating kinase-1 (ASK-1) [30], [31].

Schistosoma haematobium infection leads to urinary bladder cancer by promoting inflammation, oxidative stress. Schistosoma through infection increases the level of urinary b-glucuronidase and cyclooxygenase- 2 that promotes bladder carcinogens [32], [33].

Fasciola hepatica infection in human body induces liver fibrosis, liver cirrhosis, and hepatic cancer. Fasciola induces the expression of TGF- $\beta$ and IL-4 to inhibit activation of immune system against it. As a consequence of this, cancer cell get the immune deprived condition which is suitable for its progression and survivability [34], [35].

Clonorchis sinensis infestation is mainly linked with cholangiocarcinoma. Clonorchis sinensis induces chronic inflammation and generates oxidative stress for creating suitable microenvironment for progression of CCA. Beside this, Clonorchis also upregulates the expressions of TLR2 and TLR4 which also triggers $\mathrm{T}_{\mathrm{H}} 2$ associated cytokine production as well as suppresses $\mathrm{T}_{\mathrm{H}} 1$ cytokine. This cytokine imbalance helps in the tumorigenesis [38], [39], [40], [41].

Cysticercosis caused by the larval of Taenia solium elicits inflammatory reactions in the tissues surrounding the parasite and also in the distant tissues. Chronic infections of this parasite induce inflammatory cells to produce free radicals that help in the formation of altered tissue growth. Taenia solium also exhibits differential expression of antigens, mimics human leukocyte antigens, and alters human immune system, in such a way that the tumors can forms. Secretion of the metacestode factor by the parasite also contributes to nuclear alterations that help the cell to proliferate in a disorganized manner, leading to the possible development of neoplasia [42], [43], [44].

\section{Aschelminthes as pathogen}

Ascaris being an intestinal parasite causes pancreatic cancer when being ingested by contaminated water and food [45]. Infection with Strongyloides stercoralis induces colon adenocarcinoma by stimulating HTLV-1 replication and progression of HTLV-1-infected lymphocytes [46], [47], [48].

\section{DRUG TARGET AREA}

Antiparasitic drugs those are being proven to have also anticancer efficacy can be used more in number so that to combat parasite mediated carcinogenesis. Suramin is an anti-parasitic drug act against Trypanosoma sp also bears anti-cancer effects. Suramin blocks the angiogenesis by inhibiting VEGF, bFGF and suppresses endothelial cell proliferation [49]. Artemisinin, a well known antimalarial drug also shows efficacy to block the proliferation of human breast cancer cells by downregulating the expression of E2F1 transcription factor [50].

Antiparasitic drugs against Tapeworms and Giardia, contains a substance that kills prostate and colon cancer. Nitazoxanide, a well known and approved anti-parasitic drug decomposes the activated beta-catenin in prostate cancer [51]. Ivermectin which is being used as an important antiparasitic drugs for river blindness, strongyloidiasis, and lymphatic filariasis interacts with several targets including the multidrug resistance protein (MDR), the Akt/mTOR and WNT-TCF pathways, the purinergic receptors, PAK-1 protein, certain epigenetic deregulators such as SIN3A and SIN3B, RNA helicase, chloride channel receptors and blocks the cancer stem cells to grow [52].

Overall modulator molecules are the cytokines, growth factors that is being targeted by the Protozoan and Helminth parasites and further it leads into carcinogenesis. Therefore by applying some immunosuppressive drugs with the conventional anti-parasitic drugs might block its adverse effect towards carcinogenicity.

\section{CONCLUSION}

Overall the present review depicts the positive correlation between parasitic infection and human cancers (Fig. 1). Mostly, the Protozoan and Helminth parasites show their carcinogenic potential in humans (Table 1). Whenever the parasitic attack occurs the main modulators was found to be cytokines. Pathogen induced modulation in cytokines helps in immune escape and to create tumorigenesis in various organs. Cytokines being a growth regulatory molecule are involved in cell cycle and cellular 
ISSN No:-2456-2165

proliferation. These two cytokines dependent modulator domain is being largely targeted by the parasites to induced carcinogenicity further. In combating this, those antiparasitic drugs having anticancer efficacy shall be used more in number. Also a combinational therapy the antiparasitic drugs with the conventional chemosynthetic drugs in case of chronic infection can also be used so that to block parasite induced carcinogenicity. Drugs that particularly help to maintain cytokines status in normal are highly solicited. Though many works have already been done to develop antiparasitic drugs that furthermore can block parasite mediated carcinogenicity, however, greater amounts of work on this have been done only in in vitro condition. Further study should therefore be done in in vivo condition so that to make a better way to combat parasite induced carcinogenicity.

\begin{tabular}{|l|l|}
\hline Name of Parasites & Type of cancer \\
\hline Plasmodium $\boldsymbol{p} \boldsymbol{p}$ & Burkitts Lymphoma [6], [7],[8],[9],[10],[11],[12] \\
\hline Theileria $\boldsymbol{s} \boldsymbol{p}$ & Metastaic of leucocytes [13], [14], [15], [16], [17], [18] \\
\hline Toxoplasma $\boldsymbol{p}$ & Brain carcinogenesis [19],[20] \\
\hline Leishmania $\boldsymbol{p} \boldsymbol{p}$ & Hodgkin's disease, CD4 lymphopenia [21] \\
\hline Giardia $\boldsymbol{s} \boldsymbol{p}$ & Gastric Cancer [22],[23],[24] \\
\hline Trichonomus $\boldsymbol{s} \boldsymbol{p}$ & Cervical neoplasia [25],[26],[27] \\
\hline Cryptosporidium $\boldsymbol{s} \boldsymbol{p}$ & Gastrointestinal Cancer [28],[29] \\
\hline Opisthorchis $\boldsymbol{s p}$ & Bile duct Cancer, Chalangiocarcinoma [30],[31] \\
\hline Schistosoma $\boldsymbol{s} \boldsymbol{p}$ & Urinary bladder Cancer [32],[33] \\
\hline $\boldsymbol{F a s c i o l a} \boldsymbol{s} \boldsymbol{p}$ & Liver Cancer [34],[35] \\
\hline Clonorchis $\boldsymbol{s} \boldsymbol{p}$ & Liver Cancer, Cholangiocarcinoma [36],[37],[38],[39],[40],[41] \\
\hline Taenia $\boldsymbol{s} \boldsymbol{p}$ & Intestinal Neoplasia [42],[43],[44] \\
\hline Ascaris $\boldsymbol{s} \boldsymbol{p}$ & Pancreatic Cancer [45] \\
\hline Stronglyosides $\boldsymbol{s} \boldsymbol{p}$ & Colon Carcinoma [46],[47],[48] \\
\hline & Table 1:- Several types of carcinogenesis caused by Parasites \\
\hline
\end{tabular}

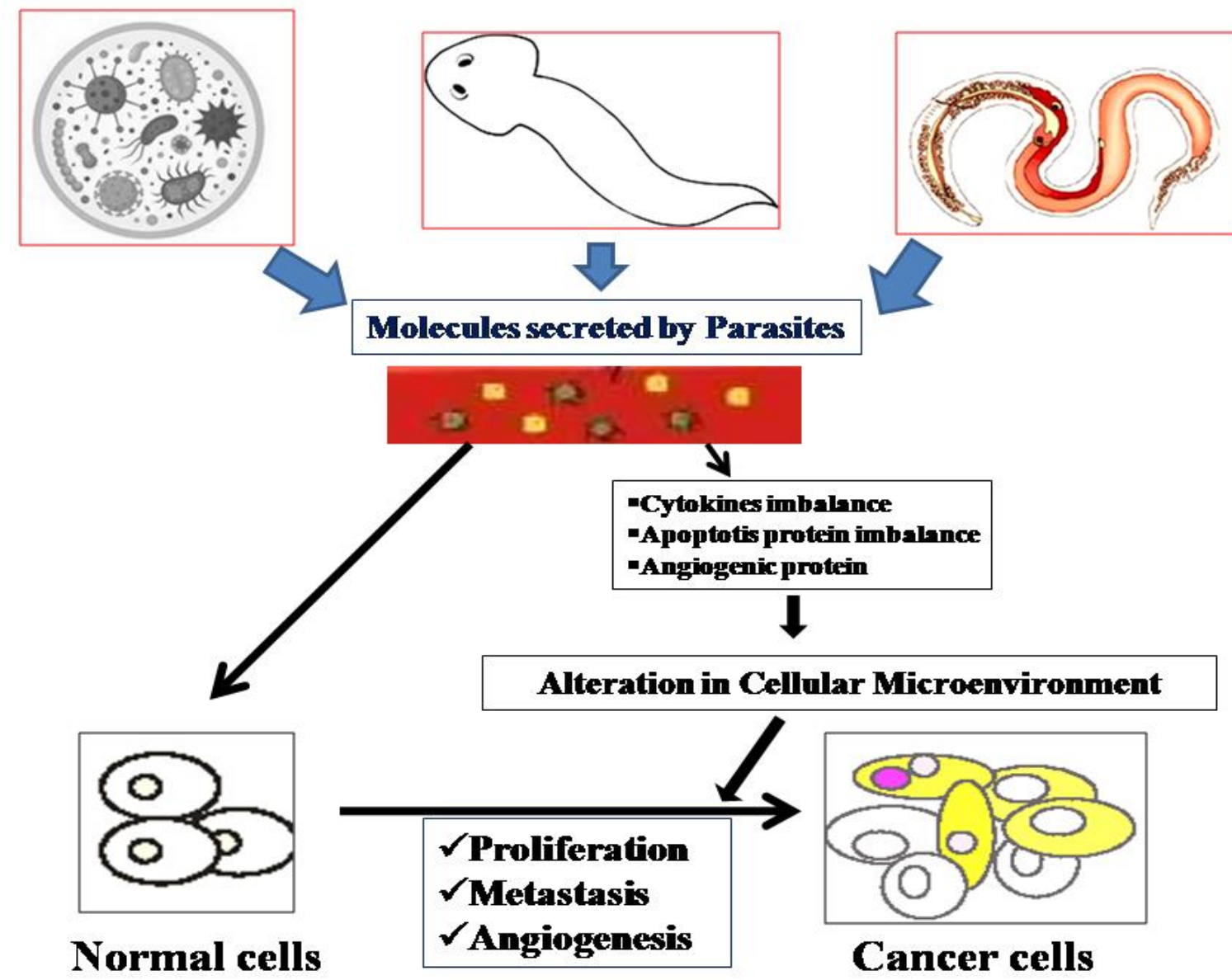

Fig. 1:- Mechanism of Parasite induced carcinogenesis. 


\section{REFERENCES}

[1]. WHO Factsheet on the World Malaria Report; 2014. https://www.who.int/malaria/media/world_malaria_rep ort_2014/en

[2]. WHO Cancer Fact Sheet No 297; 2015. http://www.who.int/news-room/factsheets/detail/cancer.

[3]. V Bouvard, R Baan, K Straif, Y Grosse, B Secretan, E GF et al, A review of human carcinogens-part B: biological agents. Lancet Oncol 10 (2009) 321-322.

[4]. IARC, 2012. A review of human carcinogens. IARC Monogr. Eval. Carcinog. Risks Hum. Biological agents 100 (Pt B) (2012) 1-441.

[5]. C deMartel, J Ferlay, S Franceschi, J Vignat, F Bray, D Forman et al., Global burden of cancers attributable to infections in 2008: a review and synthetic analysis. Lancet Oncol 13 (2012) 607-615.

[6]. E.M. Molyneux, R Rochford, B Griffin, R Newton, G Jackson, G Menon et al., Burkitt's lymphoma. Lancet 379 (2012) 1234-1244.

[7]. O Simone, M.T. Bejarano, S.K. Pierce, S Antonaci, M Wahlgren, M Troye-Blomberg et al., TLRs innate immunereceptors and plasmodium falciparum erythrocyte membrane protein 1 (PfEMP1) CIDR1alpha-driven human polyclonal B-cell activation. Acta Trop 119 (2011) 144-150.

[8]. H.C. Whittle, J Brown, K Marsh, B.M. Greenwood, P Seidelin, H Tighe et al., T cell control of Epstein-Barr virus-infected B cells is lost during $\mathrm{P}$. falciparum malaria. Nature 312 (1984) 449-450.

[9]. A.M. Moormann, K Chelimo, P.O. Sumba, D.J. Tisch, R Rochford, J.W. Kazura, Exposure to holoendemicmalaria results in suppression of EpsteinBarr virus-specific $\mathrm{T}$ cell immunosurveillance in Kenyan children. J. Infect. Dis 195 (2007) 799-808.

[10]. P.K. Chattopadhyay, K Chelimo, P.B. Embury, D.H. Mulama, P.O. Sumba, E. Gostick et al., Holoendemic malaria exposure is associated with altered EpsteinBarr virus-specific CD8(+) T-cell differentiation. J. Virol 87 (2013) 1779-1788.

[11]. R Njie, A.I. Bell, H Jia, D Croom-Carter, S Chaganti, A.D. Hislop et al., The effects of acutemalaria on Epstein-Barr virus (EBV) load and EBV-specific T cell immunity in Gambian children. J. Infect. Dis 199 (2009) 31-38.

[12]. D.F. Robbiani, S Deroubaix, N Feldhahn, T.Y. Oliveira, E Callen, Q Wang et al., Plasmodium infection promotes genomic instability and AIDdependent B cell lymphoma. Cell 162 (2015) 727-737.

[13]. R.H. Giles, J.H. van Es, H Clevers, Caught up in a Wnt storm: Wnt signaling in cancer. Biochim. Biophys. Acta 1653 (2003) 1-24.

[14]. D.A. Dobbelaered, S Rottenberg, Theileria-induced leukocyte transformation. Curr. Opin. Microbiol 6 (2003) 377-382.

[15]. V.T. Heussler, S Rottenberg, R Schwab, P Kuenzi, P.C. Fernandez, S Mckellar, B Shiels, Z.J. Chen, K Orth, D Wallach, D.A. Dobbelaere, Hijacking of host cell IKK signalosomes by the transforming parasite Theileria. Science 298 (2002) 1033-1036.
[16]. M Baumgartner, M Chaussepied, M.F. Moreau, D Werling, W.C. Davis, A Garcia, G Langsley, Constitutive PI3-K activity is essential for proliferation, but not survival, of Theileria parvatransformed B cells. Cell. Microbiol 2 (2000) 329-339.

[17]. F Dessauge, R Lizundia, G Langsley, Constitutively activated CK2 potentially plays a pivotal role in Theileria induced lymphocyte transformation. Parasitology 130 (2005) 37-44.

[18]. Lizundia R, M Chaussepied, M Huerre, D Werling, J.P. DiSanto, G Langsley, c-Jun NH2-terminal kinase/c-Jun signaling promotes survival and metastasis of B lymphocytes transformed by Theileria. Cancer Res 66 (2006) 6105-6110.

[19]. D Wang, C Qiu, H Zhang, J Wang, Q Cui, Y Yin, Human microRNA oncogenes and tumor suppressors show significantly different biological patterns: from functions to targets. PLoS One 5 (2010) e13067.

[20]. G.M. Zeiner, J.C. Boothroyd, Use of two novel approaches to discriminate between closely related host microRNAs that are manipulated by toxoplasma gondii during infection. RNA 16 (2010) 1268-1274.

[21]. O Brandonisio, R Spinelli, M Pepe, Dendritic cells in Leishmania infection. Microbes Infect 6 (2004) 14021409.

[22]. T Nagasaki, H Komatsu, Y Shibata, H Yamaguchi, M Nakashima, A rare case of gallbladder cancer with giardiasis. Nihon Shokakibyo Gakkai Zasshi 108 (2011) 275-279.

[23]. V Misra, S.P. Misra, M Dwivedi et al., Giardia lamblia trophozoites in gastric biopsies; Indian $\mathbf{J}$ Pathol Microbiol 49 (2006) 519-523.

[24]. M.C. Halliez, A.G. Buret, Extra-intestinal and long term consequences of giardia duodenalis infections. World J Gastroenterol 19 (2013) 8974-8985.

[25]. Z.F. Zhang, C.B. Begg, Is Trichomonas vaginalis a cause of cervical neoplasia? Results from a combined analysis of 24 studies. Int J Epidemiol 23 (1994) 682690.

[26]. N O'Farrell, N-Nitrosamines, trichomoniasis and cervical cancer (letter), S Afr Med J 75 (1989) 247 248.

[27]. T Ishiguro, Gas chromatographic studies on propionic acid, butyric acid and valeric acid in culture fluid of Trichomcmas uaginalis, Nippon Sanka Fujinka Gakkai Zasshi 36 (1984) 363-368.

[28]. G Certad, T Ngouanesavanh, K Guyot, N Gantois, T Chassat, A Mouray, L Fleurisse, A Pinon, J.C. Cailliez, E Deicas, C Creusy, Cryptosporidium parvum, a potential cause of colic adenocarcinoma. Infect. Agent. Cancer 2 (2007) 22.

[29]. J.C. Carmen, A.P. Sinai, Suicide prevention: disruption of apoptotic pathways by protozoan parasites. Mol. Microbiol 64 (2007) 904-916.

[30]. B Sripa, P.J. Brindley, J Mulvenna, T Laha, M.J. Smout, E Mairiang, J.M. Bethony, A Loukas, The tumorigenic liver fluke Opisthorchis viverrini-multiple pathways to cancer. Trends Parasitol 28 (2012) 395-407. 
[31]. K.R. Chng, S.H. Chan, N.G. AHQ, C Li, A Jusakul, D Bertrand et al., Tissue microbiome profiling identifies an enrichment of specific enteric bacteria in Opisthorchis viverrini associated cholangiocarcinoma. EBioMedicine 8 (2016) 195-202.

[32]. Gouveia, M.J, J Santos, P.J. Brindley, G Rinaldi, C Lopes, L.L. Santos et al., Estrogen-like metabolites and DNA-adducts in urogenital schistosomiasisassociated bladder cancer. Cancer Lett 359 (2015) 226-232.

[33]. M.P. Rosin, E Saad, S Din Zaki, A.J. Ward, W.A. Anwar, Involvement of inflammatory reactions and elevated cell proliferation in the development of bladder cancer in schistosomiasis patients. Mutation Research 305 (1994) 283-292.

[34]. M Almendras-Jaramillo, J Rivera-Medina, J SeijasMogrovejo, K Almendras-Jaramillo, Hepatic fascioliasis in children: uncommon clinical manifestations. Arq Gastroenterol 34 (1997) 241-247.

[35]. J.Y. Chung, Y.A. Bae, D.H. Yun, H.J. Yan, Y Kong, Experimental murine fascioliasis derives early immune suppression with increased levels of TGF- $\beta$ and IL-4. Korean J Parasitol 50 (2012) 301-308.

[36]. B Sripa, S Kaewkes, P Sithithaworn et al., Liver fluke induces cholangiocarcinoma. PLoS Med 4 (2007) e201.

[37]. A Maeng, H.W. Lee, Q Bashir et al., Oxidative stressmediated mouse liver lesions caused by Clonorchis sinensis infection. Int J Parasitol 46 (2016) 195-204.

[38]. [38] C Yan, X-Y Li, B Li, et al., Expression of Tolllike receptor (TLR) 2 and TLR4 in the livers of mice infected by Clonorchis sinensis. J Infect Dev Ctries 9 (2015) 1147-1155.

[39]. Y.K. Choi, B.I. Yoon, Y.S. Won, et al., Cytokine responses in mice infected with Clonorchis sinensis. Parasitol Res 91 (2003) 87-93.

[40]. E.M. Kim, Y.M. Bae, M.H. Choi, S.T. Hong, Cyst formation, increased anti-inflammatory cytokines and expression of chemokines support for Clonorchis sinensis infection in FVB mice. Parasitol Int 61 (2012) 124-129.

[41]. B.J. Vennervald, K Polman, Helminths and malignancy. Parasite Immunol. 2009;31:686-696.

[42]. J.M. Gentile, G.J. Geni. Implications for the involvement of the immune system in parasiteassociated cancers. Mutation Research 305 (1994) 315-320.

[43]. H Maeda, Carcinogenesis via microbial infection. Gan To Kagaku Ryoho 25 (1998) 1474-1485.

[44]. F Arechavaleta, J.L. Molinari, P Tato, A Taenia solium metacestode factor nonspecifically inhibits cytokine production. Parasitology Research 84 (1998) 117-122.

[45]. S Arulprakash, M.K. Sahu, A.K. Dutta, A Joseph, G.M. Chandy, Pancreatic ascariasis with periampullary carcinoma. Trop Parasitol 5 (2015) 55-57.

[46]. T Tanaka, T Hirata, G Parrott, M Higashiarakawa, T Kinjo, $\mathrm{T}$ Kinjo et al., Relationship among strongyloides stercoralis infection, human T-cell lymphotropic virus type 1 infection, and cancer: a 24- year cohort inpatient study in Okinawa, Japan. Am.J.Trop. Med. Hyg 94 (2016) 365-370.

[47]. A.S. Gabet, F Mortreux, A Talarmin, Y Plumelle, I Leclercq, A Leroy et al., High circulating proviral load with oligoclonal expansion of HTLV-1 bearing T cells in HTLV-1 carriers with strongyloidiasis. Oncogene 19 (2000) 4954-4960.

[48]. M Satoh, H Toma, K Sugahara., K Etoh, Y Shiroma, S Kiyuna, et al., Involvement of IL-2/IL-2R system activation by parasite antigen in polyclonal expansion of CD4(+)25(+) HTLV-1-infected T-cells in human carriers of both HTLV-1 and S. stercoralis. Oncogene 21 (2002) 2466-2475.

[49]. Gajanan V. Sherbet, Molecular Approach to Cancer Management.Academic Press (2017)149-150. doi.org/10.1016/B978-0-12-812896-1.00016

[50]. A.S. Tin, S.N. Sundar, K.Q. Tran, A.H. Park, K.M. Poindexter, G.L. Firestone, Antiproliferative effects of artemisinin on human breast cancer cells requires the downregulated expression of the E2F1 transcription factor and loss of E2F1-target cell cycle genes. Anticancer Drugs 23 (2012) 370-379.

[51]. University of Bergen. "Tapeworm drug fights prostate cancer." 2017. www.sciencedaily.com/releases/2017/11/17111409185 0.htm. 2017.

[52]. M Juarez, A Schcolnik-Cabrera, A Dueñas-Gonzalez, The multitargeted drug ivermectin: from an antiparasitic agent to a repositioned cancer drug. Am J Cancer Res 8 (2018) 317-331. 